\title{
Healing the City: Elemental Constructions and the Universal Language of Architecture
}

\author{
MERSIHA VELEDAR
}

The Cooper Union

\begin{abstract}
There is a bridge in the city I knew in my childhood, a bridge so breathtaking, one would not believe that within its many layers of smooth tenelia stone, there lie millions of eggshells tectonically binding what was once known as the widest arch in the world of that era. Having lived through the dissolution of the seven states that comprised the melting pot of former Yugoslavia and the 1992-1995 brutal genocide of Bosniaks in Mostar, a city of ancient bridge-keepers known as "Mostari," I've directly witnessed the effects of man-made disasters as a strategic form of cultural erasure. This paper aims to critically explore my search towards 'universality' in the language of architecture vis-à-vis a sequence of elemental typologies as the new design objective that could challenge and begin to heal variant sites that have endured political, economic and cultural injustices across the world.
\end{abstract}

"Anything can happen, the tallest things be overturned, those in high places be daunted. Ground gives. Heavens' weight lifts up off Atlas like a kettle lid. Capstones shift. Nothing resettles right. Smoke furls and boiling ashes darken day."

-After Horace, Odes 1, $34^{1}$ - translated by Seamus Heaney

\section{WITNESSING DESTRUCTION}

Having directly witnessed and survived the effects of war and genocide, I understood early on the deep resilience of 'architecture' inside the civic infrastructure of a city.

All schools, universities, theaters, hospitals, parks, markets, and six public bridges that highlighted Mostar's unique history were strategically destroyed as part of an initiative to erase a mélange of public structures needed to keep the city context functioning and its memory alive. After twenty-five years to date since the peace Dayton accord, Mostar still remains a divided city in Europe, split in half between the newly acquired 'Croatian' and the indigenous 'Bosnian' side. Having been first occupied in 1992 [to the east side of the Neretva River] by the Serbian military, Mostar was consequently annexed overnight [to the west] on May 9th, 1993 by the Croatian military. New families were imported to live in the previously Bosnian households marking themselves now as 'Bosnian-Croat', while inventing softened nomenclature towards a perfectly confusing alibi in the attempts to mask the final acts of genocide and war coined 'urbicide'. This massive population influx was supported by the then Croatian President Franjo Tudzman while the spoils of war propagated an instant economic gain towards the aggressors left in power. Less than $20 \%$ of original Mostarian citizens remain today. Of its 126,000 citizens, close to 40,000 left prior to the war. ${ }^{2}$ Around 10,000 male citizens were forcibly detained in local prison camps and more than 30,000 remained in the city but were forced to leave their households through remarkably violent means and methods. After 427 years, the iconic bridge was destroyed by the Croatian military on November 9th, 1993 while the ricochet of bullets celebrated its fall as an index of the previous Ottoman culture. ${ }^{3}$ Year 2017 marks the culmination of the longest standing trial to-date at the War Crimes Tribunal in The Hague that sentenced key generals who committed crimes against humanity and acts of genocide on this ground. ${ }^{4}$

\section{MONUMENTAL ICONS, PRESERVATION AND ERASURE OF FACTS}

Currently, the city is suffering through another architectural disaster in the form of urban preservation where the majority of post-war edifices are sterilized and rebuilt in an identical pre-war veneer that provides the perfect alibi in what may be referred to as the architecture of denial. In this occurrence, the acts and memories of war are paradoxically erased both by the actual perpetrators and victims of war. While there could be a valid argument that cultural iconography of the Stari Most bridge should be rebuilt in order to provide the necessary infrastructure and spatial iconography, it is challenging to witness the soft colored palettes of housing blocks erasing the effects of war alongside the main demarcation Boulevard lines without a direct challenge to the social and cultural algorithm that could and should be reinvented if we are to hope that history will not repeat itself. In Roman Antiquity, 'damnatio memoriae' condemns memory of an individual and the nostalgic desire to reverse and glorify the past. ${ }^{5}$ If we are to challenge history, the same framework could be applied to architecture as an inventive act of design that is rooted in various methods of experimentation and architectonic exposure of actual facts through the evasion of the post traumatic denial.

\section{CAPTURING ATMOSPHERES THROUGH}

UNIVERSAL ELEMENTS

What do alternative nations share, have in common, and cannot politically corrupt?

In my own research, I began to view the fundamental language of architecture through the mask of universal elements 
of 'nature' such as air, water, and wind which we all share, regardless of ethnicity, religion, or race. In parallel, domesticscale universal elements such as walls, doors, windows, stairs, columns, skylights, and additional domestic objects are chosen as the foundational lexicon to be used and re-invented within the programmatic restrictions of unifying functions of nature. This universality is programmatically twofold where the atmospheric effects of nature could become the binding functional agent of experimentation and innovation. These elemental frameworks come with a particular set of disciplines, opportunities, challenges, and histories as the fundamental vocabulary of architecture that could be applied as the search towards universality in post-disaster sites as novel experimental methods towards healing of the city.

Lebbeus Woods famously proclaimed in his proposed project for the rebuilding of Sarajevo that the "Wall would become a City. Walls can become an armature for transformation, an instrument not for dividing and separating, but for bringing opposing ideas and people together." ${ }^{6}$ In his view, the radical advent of architecture lies in its desire towards experimentation and invention of the elemental precedent. Additionally, these elements have been exposed to tectonic filters of nature and variant atmospheres, while articulating spatial, structural and material notions of 'universality' even under explicit religious undertones.

The atmospheric experience of reflections and refractions and the effects of nature being challenged through the advent of tectonic grain in search for 'light', are demonstrated within the 5,000 muqarna prismatic modules in the ceilings of the 'Hall of Two Sisters in Alhambra /Wonders of the World' [1238] as an extraordinary undertaking that cannot deny its structural aim towards a universal language in architecture and the cosmological orders also described as a 'celestial explosion' by Robert Irwin. ${ }^{7}$ Not so far away, the dome of Santa Maria del Fiore by Fillipo Brunelleschi [1418] in Florence shows a heroic structural span where the double vault holds an incredible inner staircase as it folds along the geometry of the dome's hidden surface and its tectonic pathway towards the central oculus.

In 1851, Semper's attempt at the universal theory of architecture is tested in his seminal text the 'Four Elements of Architecture ${ }^{\prime 8}$ where the tectonic and cultural origins of architectures are described through the spatial mechanisms of wall and roof enclosures, the hearth and the mound. This text sets up the technological framework towards spatial function as a system of assembly, construction and reconstruction that is indigenous to the rudimentary sequence of elements as articulated in an act of [domestic] survival.

Casa Antonio Galvez in Mexico City by Luis Barragan (1954) tests the idea of a courtyard as a sun apparatus where the window element can be used to trace shadows and time through the conceptual framework of a constructed sundial. The window, embedded within the element of a wall, begins to dissolve the boundaries between outside and inside through animation in color and materiality. The omission of spandrel panel and lintel allows Bo and Wohlert to create Louisiana Museum in Humblebaek (1958) while reinterpreting the idea of a 'wall' as a fully transparent interface, bringing the ethereal reciprocity of elements of nature within the perception of the interior museum cavity.

\section{SPECTACLE OF DESTRUCTION AND CONSTRUCTION}

Jan Kempenaers surveyed in 2008 a sequence of Balkan monuments known as 'spomeniks' throughout the terrains of former Yugoslavia. In the audacious search of these magnificent looking structures, the spectacle of construction and destruction was memorialized within their tectonic and symbolic lineages. These seemingly magnificent structures instill the power of awe in a novel audience and yet what is not immediately visible on the very surface is that these structures mark an array of sites that have endured horrific turmoil, marking locations of mass graves and genocide from the aftermath of the previous WWI, WWII wars. ${ }^{9}$ Moving past the symbolic monuments, in the current 2018 exhibition "Toward a Concrete Utopia: Architecture in Yugoslavia, $1948-1980$ " at the MoMA in New York, the claimed utopian paradox neglects to mention that the majority of the 20th century avant-garde projects that took on notions of creating civic programs throughout Bosnia and Herzegovina (from mosques to theaters and such), were for the most part brutally decimated by the surrounding armies leaving a nostalgic void within the victimized terrains. On the other end, the spectacle of destruction as an impetus towards novel methods of experimentation, has inspired the works of Lucio Fontana (canvas cutting), Gordon Matta Clark (house slicing) and Yves Klein 'Fire Paintings' where he uses a burner to draw elemental outlines of 'columns' at full scale. Fontana's metal and material canvases also play with the notion of dimensionality..$^{10}$ They have been slashed and pierced to allow the viewer access to the space beneath the surface as an action of destructive beauty that is also amplified in his canvas works after WWII. These methods of abstraction beg the question if the spectacle of destruction can be contradicted by the spectacle of construction as an amplified method of experimental invention, while contained and defined by the moral practice of architecture.

\section{ON SCALE AND URBAN UNIVERSALITY}

At the height of the Iraq war, Jean-Luc Godard, in his 2004 film "Notre Musique" ${ }^{11}$ (Our Music), dichotomizes in a tripartite filmic structure inspired by the Divine Comedy of Dante ${ }^{12}$ under "Part 1: Inferno" "Part 2: Purgatory," and "Part 3: Paradise" a collage of disasters that capture violence, lapses in morality and acts of colonialism. This film, like any work of great literature, is not easy to view as it blurs in a historically overlapped manner the aftermath and 
global consequences of war, justifiably described by one character's interpretation as "violence leaves a long scar."

This film tells the story of two young women visiting a European arts conference in Sarajevo: a journalist from Tel Aviv and a French-speaking Jew of Russian descent. They interview the Palestinian poet Mahmoud Darwish (played by himself) and survey the destroyed city of Mostar, visiting the rebuilding of the ancient bridge above the emerald river where one sees the prolonged effects of destruction. One of the key frames shows a Native American tribe standing directly underneath the metal clad reconstruction of the 'Stari Most' bridge as a visual analogy to the erasure of the Native American culture in the United States and the erasure of the Bosniaks in Mostar, Bosnia and Herzegovina.

This film resonates now more than ever and tests if we might reach what Godard calls "heaven" through a civic mind-set shown clearly in one character's statement: "Humane people don't start revolutions. They start libraries," as a key shot zooms on the burning of the National Library of Sarajevo, which held 1.5 million volumes and over 155,000 rare books and manuscripts. [It was built in 1896 and destroyed in 1992.] As architects, we have a deep responsibility to address every aspect of urban resiliency. This resilient framework [regardless of the areas of the world that continue to endure duress under war] is seen through the advent of civic programs.

It is also important to highlight critical scales through which urbanism is activated. From details, to buildings to master plans, back and forth these multiple scales andrealities become a critical design algorithm. In search of universality, one could argue that the urban interpretation of public structures that are' common' to all city fabrics include facades, corners, roofs, pavements, and streets where multiplicity of elemental transformations became a universal urban assemblage.

The work of Ray and Charles Eames (1968) uses projections in scale in their seminal "Powers of Ten" ${ }^{13}$ documentary, based on the adaptation of the 1957 book 'Cosmic View'.${ }^{14}$ This cosmological reading once again engages with elements of nature, technology and advents in biology as demonstrated through a sequence of scalar projections in orthographic plan. The social interface (eating and communicating together) gives a visual glimpse of another vital living ritual.

\section{MORAL PREDICAMENT}

This sequence of research shows glimpses of moral consciousness where we have an opportunity as architects to act on the variant aftermaths of violence through the universally elemental strategies in architecture and their potential to influence change at any scale of thought. In this sense, architecture is a deeply political force. With it, our values and identities can be canonized or destroyed. Universal typologies of elements have the potential to transcend geographic boundaries through the introduction of a 'common ground' where spatial norms are to be questions and new inventive possibilities are to be discovered. This elemental foundation creates a framework of familiarity that focuses attention on cultural similarities and dissuades aggressors from their intermittent attempts to subjugate or destroy the differences. The fundamental lexicon discussed here is highlighted through the significance of civic spaces, living rituals and the potential of elemental systems (wall, ceiling, window, stair and such) to be activated through the 'healing' elements of nature. Le Corbusier claimed that the history of architecture could be examined as a struggle in search for light..$^{15}$ In conclusion, it is important to recognize and understand the fragility of the human body in parallel with the fragility of architecture where new conscientious design approaches towards novel tectonic, material, programmatic and technological advances must be explored and tested in order to sustain a more inventive future for the world and our next generations.

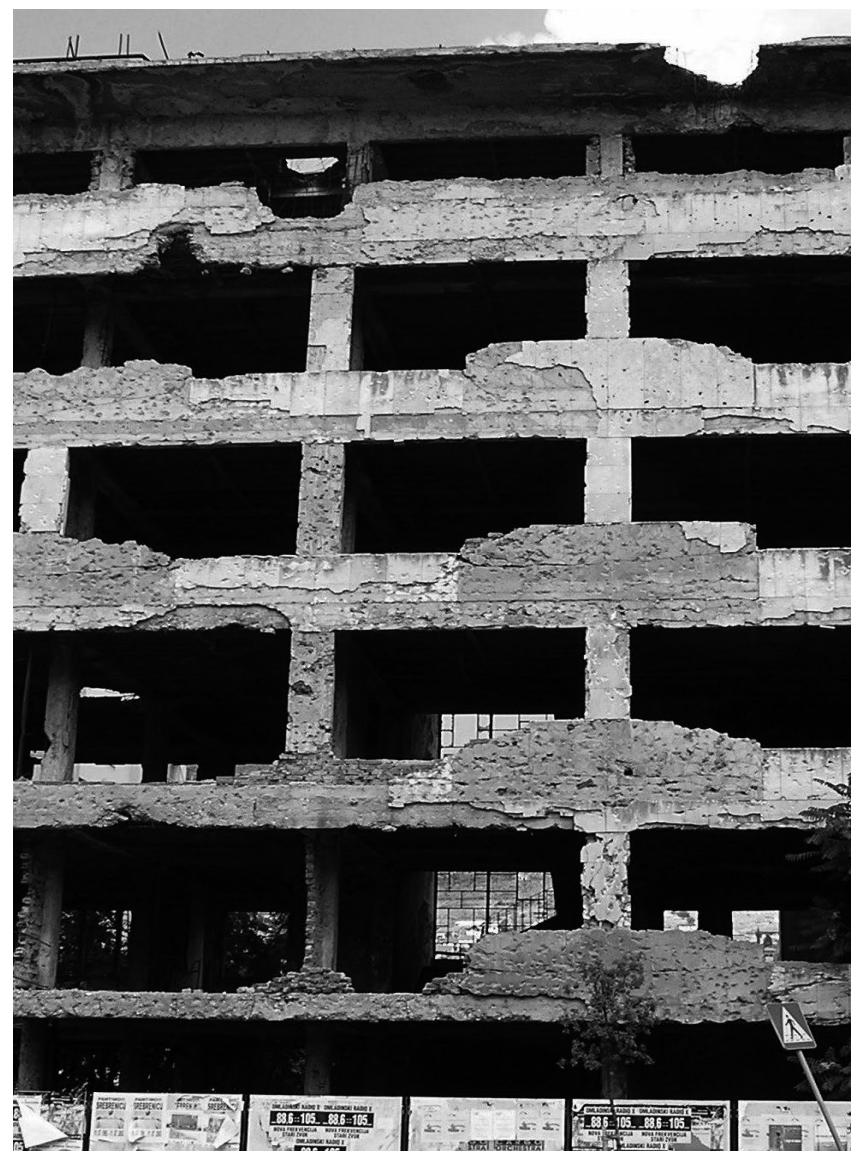

Figure 1: Main Boulevard in Mostar [housing] 43 20' N17 48' E, Bosnia and Herzegovina, taken by the author in 2004 


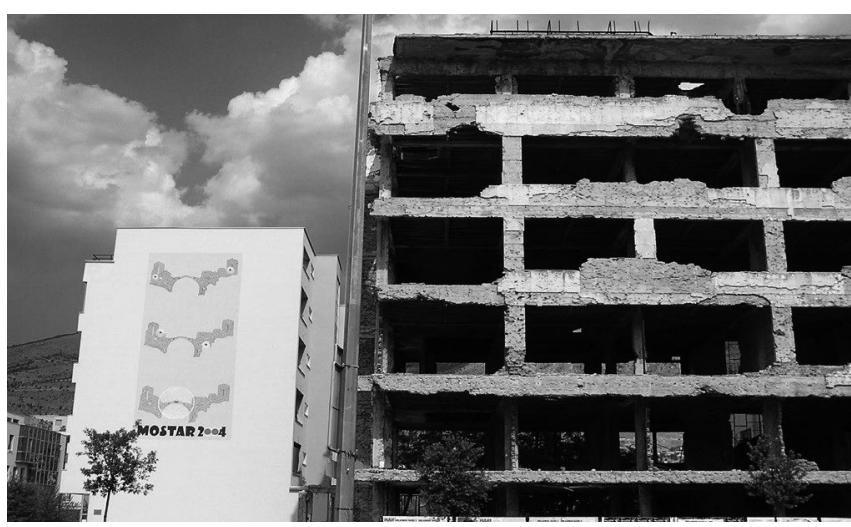

Figure 2: Main Boulevard in Mostar [department store] 43 20' N17 48' E, Bosnia and Herzegovina, taken by the author in 2004

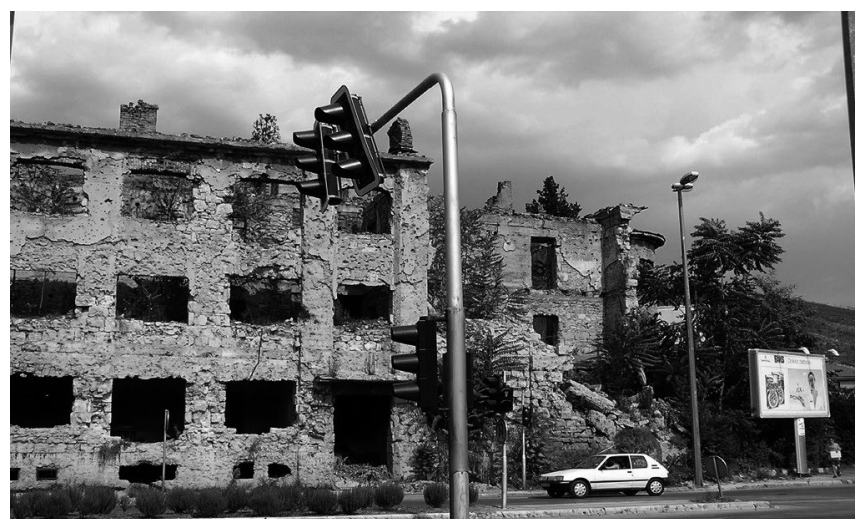

Figure 3: Main Boulevard in Mostar [residential housing] 43 20' N17 48’ E, Bosnia and Herzegovina, taken by the author in 2004

\section{ENDNOTES}

1. Heaney, Semus, Anything can Happen, a poem and an essay by Seamus Heaney with 24 translations in support of art for amnesty, Town House, 2004.

2. Calame, Jon and Charlesworth, Esther, Divided Cities: Belfast, Beirut, Jerusalem, Mostar and Nicosia; University of Pennsylvania Press, May 18, 2012.

3. Jeremy Bowen (1993) BBC Documentary “Unfinished Business - War in Mostar;" presented by Jeremy Bowen (BBC) / filmed in and around Mostar at the height of the Bosniak-Croat conflict during the Bosnian War. Bowen
himself recent appeared a war crimes trial at The Hague, where the documentary was featured as evidence.

4. Opray, Max, "Bosnian Croat war criminal dies after taking poison in UN courtroom," The Guardian, 2017.

5. Varner, Eric R., (2004). "Monumenta Graeca et Romana: Mutilation and transformation : damnatio memoriae and Roman imperial portraiture; Brill (1750).

6. Woods, Lebbeus, Radical Reconstruction, Princeton Architectural Press, May 7, 2001

7. Lebbeus Woods, Radical Reconstruction, Princeton Architectural Press, May 7, 2001.

8. Semper, Gottfried, 'Die vier Elemente der Baukunst/ The Four Elements of Architecture,' translated by Harry F. Mallgrave and Wolfgang Herrmann, 1851.

9. Kempenaers, Jan, Spomenik by Willem Jan Neutelings, 2015

10. Renato Barilli, Lucio Fontana, MoMA Collection.

11. Godard, Jean Luc, 'Notre Musique' [Our Music]; Cannes Film Festival, 2004

12. Aligheri, Dante, "The Divine Comedy," 1308.

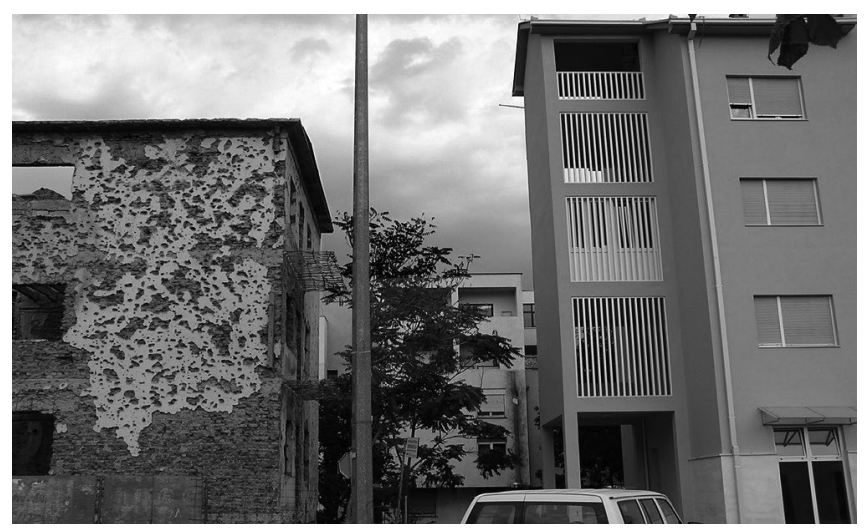

Figure 4: Main Boulevard in Mostar [residential housing] 43 20' N17 48' E, Bosnia and Herzegovina, taken by the author in 2004

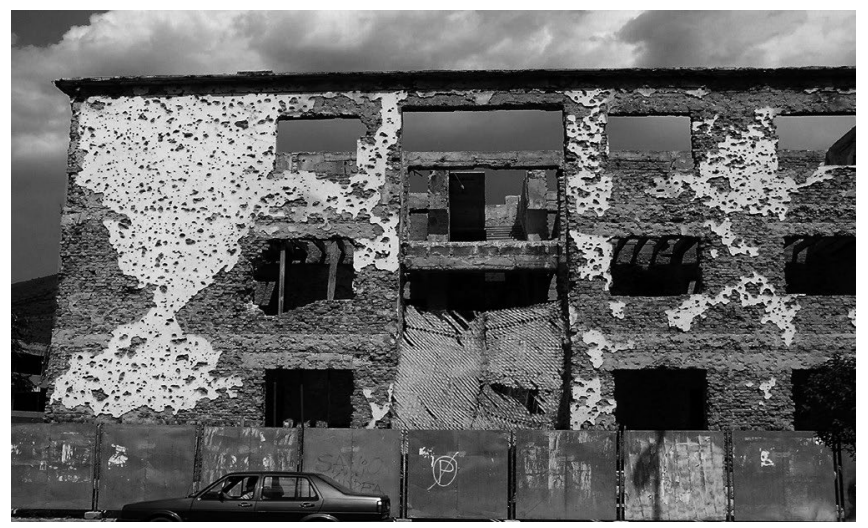

Figure 5: Main Boulevard in Mostar [residential housing] 43 20' N17 48' E Bosnia and Herzegovina, taken by the author in 2004

13. Eames, Ray and Charles, "Powers of Ten" documentary; Public Broadcasting Service (PBS), 1968

14. Boeke, Kees, "Cosmic View: The Universe in Forty Jumps;” J. Day, 1957.

15. Le Corbusier, Towards a New Architecture, Martino Fine Books, 1927. 